\title{
White Crystals Controversy: Sugar rather than Salt as the Etiology of Hypertension
}

Tiny Nair

\begin{abstract}
Traditionally, salt intake is linked to hypertension, and salt restriction forms the foundation for "lifestyle" management of hypertension. Despite an increase in incidence of hypertension in the population, data did not show any increase in salt intake over longer time frame. Increased intake of processed food amounts to increase in sugars especially fructose. Rampant and excessive commercial use of high fructose corn syrup in ready-to-eat "fast" food results in hypertension by various mechanisms. This interesting shift of concept of white crystals from salt to sugar is reviewed in this commentary.
\end{abstract}

Keywords: High fructose corn syrup, Hypertension, Salt, Sugar.

How to cite this article: Nair T. White Crystals Controversy: Sugar rather than Salt as the Etiology of Hypertension. Hypertens J 2016;2(1):7-9.

\section{Source of support: Nil}

\section{Conflict of interest: None}

\section{SALT AND HYPERTENSION}

High blood pressure (BP) is a major contributor to cardiovascular morbidity and mortality. ${ }^{1}$ It is traditionally believed that sodium retention is a major cause for hypertension, which is mediated through volume expansion as well as an increase in stiffness of vascular system. Dietary salt is implicated as the major determinant of body sodium. Restriction of dietary salt has been considered a major nonpharmacologic method of controlling BP. ${ }^{2}$ Diuretics act by reducing body sodium. Most other BP-lowering medications get their effect amplified several folds when salt restriction is strictly enforced. The Cochrane systemic review ${ }^{3}$ looked at the effect of modest amount of salt restriction on BP. The data show that 100 mmols of reduction of urinary sodium excretion per day (equivalent to 6 grams of dietary salt/day) resulted in reduction of systolic blood pressure (SBP) of $5.8 \mathrm{~mm} \mathrm{Hg}$. It has been estimated that the highest $v$ s lowest quartile of salt intake significantly reduced cardiovascular events in both sexes in all ethnic Head
Department of Cardiology, PRS Hospital, Thiruvananthapuram
Kerala, India

Corresponding Author: Tiny Nair, Head, Department of Cardiology, PRS Hospital, Thiruvananthapuram 695002 Kerala, India, Phone: 9847061455, e-mail: tinynair@gmail.com population as well as at all levels of body mass indexes (BMIs). Salt intake reduction from 10 to $5 \mathrm{gm}$ daily is estimated to reduce stroke incidence by $24 \%$, cardiovascular (CV) events by $18 \%$, and avoid 2.5 million deaths annually worldwide. The World Health Organization (WHO) recommends salt restriction as a lifestyle measure to reduce $\mathrm{CV}$ event rate in the population. ${ }^{4}$

\section{Data of Salt Intake in Population}

It is known that 24-hour urinary sodium excretion in an individual is an objective evidence of the amount of salt intake in that individual. In fact, population-level salt consumption is reliably measured by measuring 24-hour urinary sodium excretion in that population. The Global Burden of Diseases Nutrition and Chronic Diseases Expert Group (NUTRICODE) data ${ }^{5}$ published in NEJM analyzed global urinary sodium excretion data and translated it to model and predict $\mathrm{CV}$ death rate. The analysis showed an estimated 1.65 million CV death attributed to salt intake higher than 2 gm per day. The prospective urban-rural epidemiology (PURE) study 6 showed an interesting U-shaped relation between salt intake and CV event rate and mortality, as assessed by urinary sodium excretion. A urine sample of 101,945 people in 17 countries was analyzed, showing lowest $C V$ events and mortality in those consuming 3 to 6 gm salt. A lower intake than $3 \mathrm{gm}$ or a higher intake than $6 \mathrm{gm}$ increased the $\mathrm{CV}$ event and mortality rate. In an interesting meta-analysis published in 2010 in the American Journal of Nutrition, ${ }^{7}$ the authors looked at 24-hour urinary sodium excretion (which parallels salt intake), which shows very little variation over a 30-year period from 1970 to 2000. A new analysis of data by NHANES ${ }^{8}$ looked at sodium excretion from 2001 to 2010 and came out with similar results. In this study, urinary 24-hour salt excretion remained uniform and stable in all ethnic subgroups, despite varying food patterns. This indicates that the sodium intake of the American Population over the last 50 years did not change substantially. Despite a stable salt intake, the incidence of hypertension has increased. Consequent to increase in incidence of hypertension, target organ damage (stroke, CV events, nephrosclerosis) also increased in parallel over the same period. Over time, lifestyles have changed, with a change in dietary pattern leading to increased intake of processed food. This brings 
us to the question whether the culprit could be some other component of the processed food, rather than salt.

\section{Sugar and Hypertension}

Gerald Reaven in $1987^{9}$ published an article in the Journal of Hypertension showing that fructose-fed rats, became obese, developed insulin resistance. Interestingly, he also noted that those rats developed an increase in BP. Today, we know that fructose in diet causes hypertension by multiple mechanisms, by direct effect, indirectly by creating more metabolic syndromes, or by increasing uric acid.

\section{Sugar and Uric Acid}

The metabolism of uric acid in humans is interesting and complex. In an unusual mutation of a codon 33, which occurred 25 million years ago, human beings lost an enzyme called uricase, an enzyme that metabolizes uric acid to allantoin and then subsequently to ammonia and carbon dioxide (Flow Chart 1). Thus, humans tend to accumulate uric acid and the only way of excretion of uric acid in humans is the kidneys, through urine. Fructose

Flow Chart 1: Uric acid metabolic pathway. Humans lack uricase enzyme and tend to accumulate uric acid
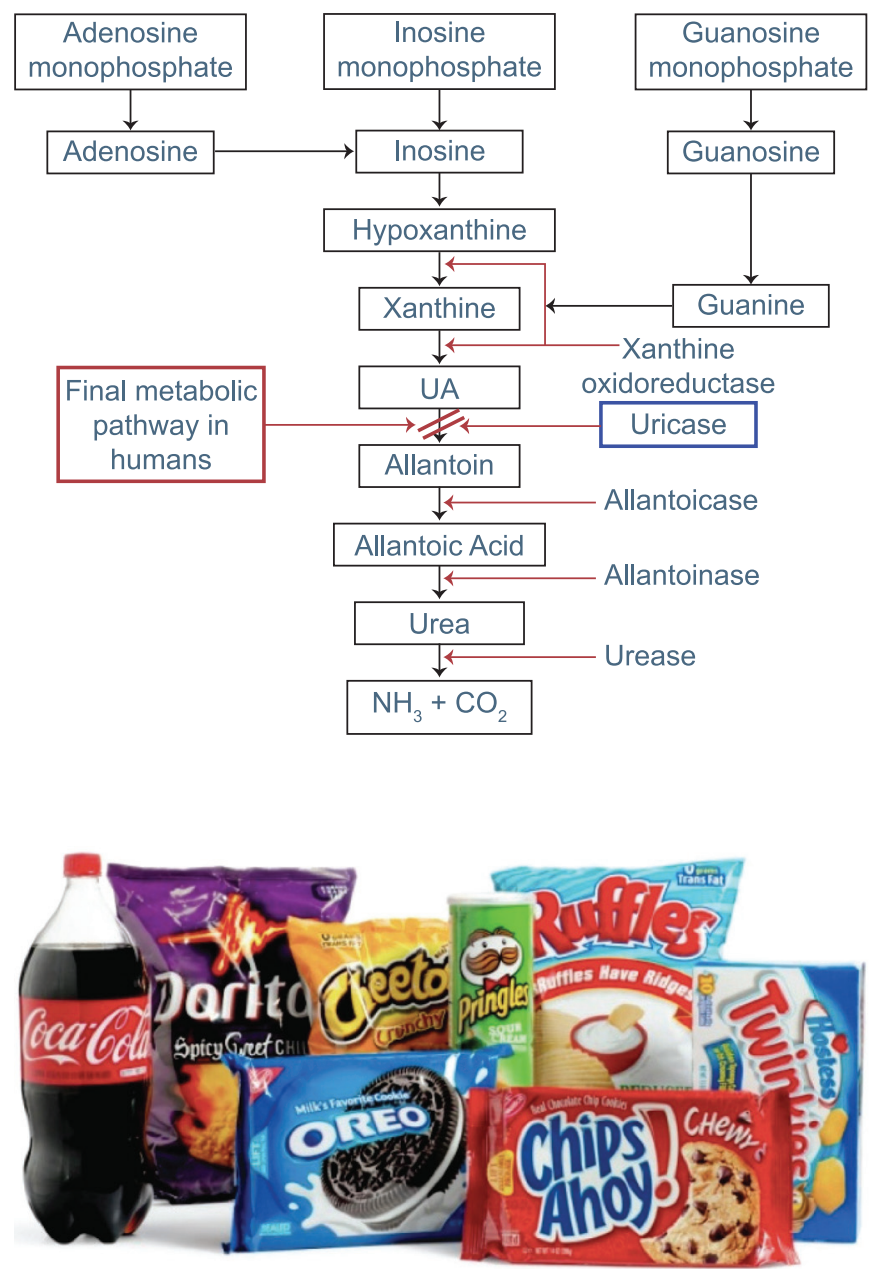

Fig. 1: Food containing high-fructose corn syrup in processed food, by complex metabolic pathway, gives rise to triglycerides and uric acid (Flow Chart 2).

\section{High-fructose Corn Syrup}

Of the sweetening agents available (glucose, fructose, and sucrose) fructose derived from corn syrup, highfructose corn syrup (HFCS), has the maximum sweetness. It can also be bulk manufactured at a cheap price. Most readymade ready-to-eat fast food available over the counter-biscuits, cookies, chips, crackers, and softdrinks (cola) contain high level of HFCS (Fig. 1).

In a study published in JAMA in 2000, Fang et $\mathrm{al}^{10}$ showed that a higher quantity of uric acid is associated with higher CV disease mortality. The possible mechanisms by which fructose produce hypertension are depicted in (Flow Chart 3).

\section{Salt and Hypertension-New Concept}

In an interesting concept, DiNicolantonio and Lucan, in an article published in Open Heart, ${ }^{11}$ proposed that sugar rather than salt may be more important in

Flow Chart 2: Fructose metabolism pathway. The end product is uric acid and triglyceride

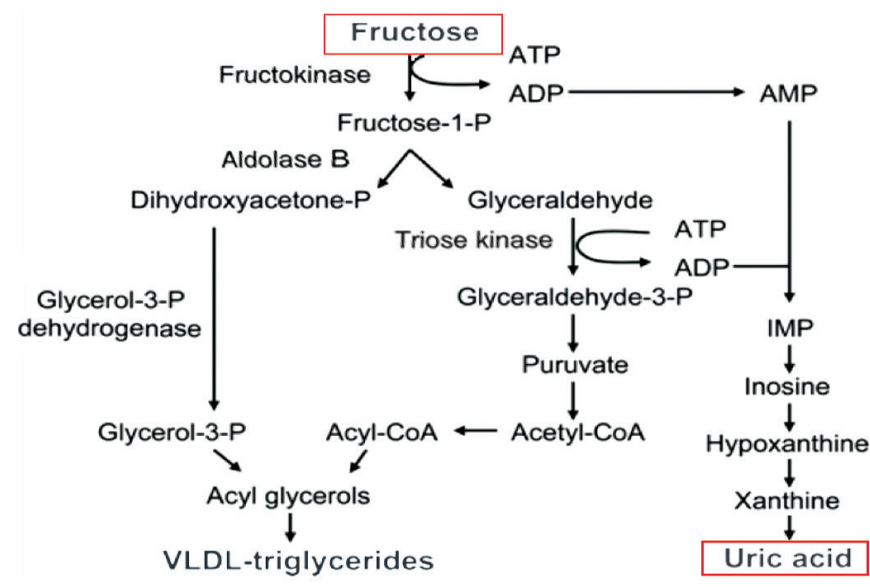

Flow Chart 3: Possible mechanisms of dietary fructose producing hypertension

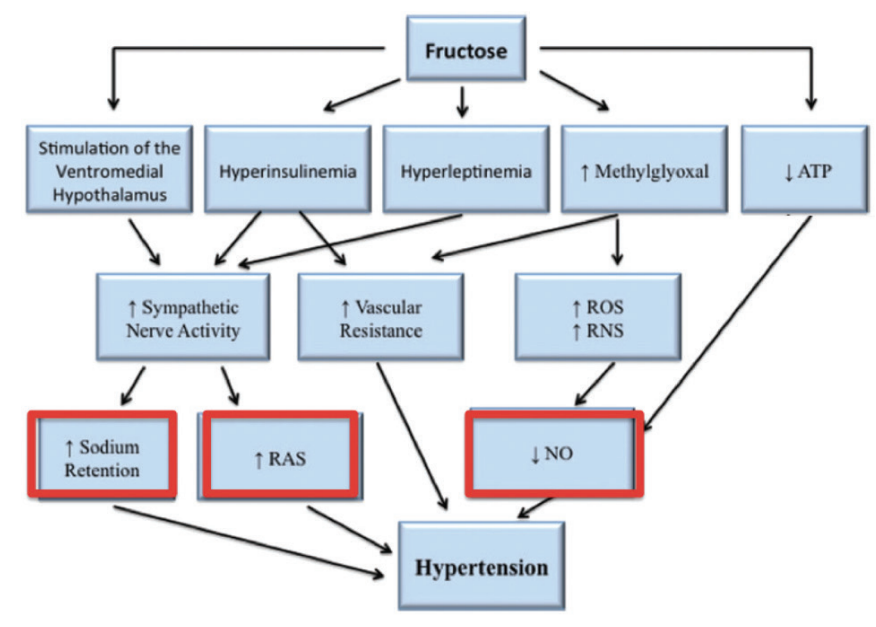


creating hypertension in a population especially those in developed countries. A policy of widespread sodium restriction in processed "fast" over-the-counter food makes people take more of such food to satisfy their salt craving. This could explain the constant nature of urinary salt excretion in the population. The higher burden of processed food means higher fructose intake, a higher uric acid level, and increased incidence of cardiometabolic syndrome as well as hypertension.

In a meta-analysis by Te Morenga et al, ${ }^{12}$ higher sugar intake resulted in an increase in BP (6.9 $\mathrm{mm} \mathrm{Hg}$ systolic and $5.6 \mathrm{~mm} \mathrm{Hg}$ diastolic) compared with those with low sugar intake. In a short-term trial, high-fructose diet increased BP by $7 \mathrm{~mm} \mathrm{Hg}$ systolic and $5 \mathrm{~mm} \mathrm{Hg}$ diastolic, as well as heart rate by $4 \mathrm{bpm}$, over a 2-week period. ${ }^{13}$ Yang et $\mathrm{al}^{14}$ compared the $\mathrm{CV}$ mortality of patients with calorie intake from added sugars. Those consuming $10 \%$ to $24 \%$ calorie from added sugar had a $30 \%$ increase in mortality compared with those consuming less than $10 \%$, while those with more than $25 \%$ calorie from added sugars had a threefold increase in risk.

\section{Controversy}

The salt-hypertension controversy continues to simmer. The 2016 issue of International Journal of Epidemiology published an entire series on the subject, centering upon a report by Trinquart et $\mathrm{al}^{15}$ on polarization of the two groups on the topic. They showed that both supporters and antagonists tend to blindly cite and quote their side of the story. Both groups keep "shouting their opinion from the top of two hills, while people in the valley are clueless" is how the editors put it as eminent scientists mark their opposing views on the topic. This reminds us that much remain to be explored than that meets the eye.

\section{CONCLUSION}

Salt is traditionally implicated as an important etiological factor in hypertension, playing a crucial role in genesis and propagation of hypertension, as well as target organ damage. But there may be other metabolic factors such as dietary fructose that result in direct and indirect elevation of BP. Data indicate that HFCS in ready-to-eat food might be responsible for elevation of $\mathrm{BP}$ and creation of metabolic syndrome. Reduction of fructose intake in food (especially commercial sweeteners such as HFCS) as a policy in the population might go in a long way in reducing the incidence and complication and overall burden of the high BP.

\section{REFERENCES}

1. Lim SS, Vos T, Flaxman AD, Danaei G, Shibuya K, AdairRohani H, Amann M, Anderson HR, Andrews KG, Aryee $\mathrm{M}$, et al. A comparative risk assessment of burden of disease and injury attributable to 67 risk factors and risk factor clusters in 21 regions, 1990-2010: a systematic analysis for the Global Burden of Disease Study 2010. Lancet 2012 Dec 15;380(9859):2224-2260.

2. Graudal NA, Galloe AM, Garred P. Effects of sodium restriction on blood pressure, renin, aldosterone, catecholamines, cholesterols, and triglyceride: a meta-analysis. JAMA 1998 May 6;279(17):1383-1391.

3. He FJ, Li J, MacGregor GA. Effect of longer term modest salt reduction on blood pressure: cochrane systematic review and meta-analysis of randomized trials. BMJ 2013 Apr 3;346:f1325.

4. Mozaffarian D, Fahimi S, Singh GM, Micha R, Khatibzadeh S, Rebecca E. Global Burden of Diseases Nutrition and Chronic Diseases Expert Group (NUTRICODE). N Engl J Med 2014;371:624-634.

5. O'Donnell M, Mente A, Rangarajan S, McQueen M J, Wang X, Liu L, Yan H, Lee SF, Mony P, Devanath A, et al. For the PURE Investigators: Urinary sodium and potassium excretion, mortality, and cardiovascular events. N Engl J Med 2014 Aug 14;371(7):612-623.

6. World Health Organization. Population sodium reduction strategies: Global Strategy on Diet, Physical Activity and Health. Geneva: World Health Organization; 2014.

7. Bernstein AM, Willett WC. Trends in 24-h urinary sodium excretion in the United States, 1957-2003: a systematic review. Am J Clin Nutr 2010 Nov; 92(5):1172-1180.

8. Fulgoni V L, AgarwalS, Spence L, Samuel P. Sodium intake in US ethnic subgroups and potential impact of a new sodium reduction technology: NHANES Dietary Modeling. Nutr J 2014 Dec 18;13(1):120.

9. Hwang IS, Ho H, Hoffman BB, Reaven GM. Fructose induced insulin resistance and hypertension in rats. Hypertension 1987 Nov; 10(5):512-516.

10. Fang J, Alderman MH. Serum uric acid and cardiovascular mortality, the NHANES I epidemiologic follow-up study, 1971-1992. JAMA 2000 May;283(18):2404-2410.

11. DiNicolantonio J, Lucan SC. The wrong white crystals not salt but sugar as etiological in hypertension and cardiometabolic disease. Open Heart 2014 Nov 3;1(1):e000167.

12. Te Morenga LA, Howatson AJ, Jones RM, Mann J. Dietary sugars and cardiometabolic risk: systematic review and metaanalyses of randomized controlled trials of the effects on blood pressure and lipids. Am J Clin Nutr 2014 Jul;100(1): 65-79.

13. Perez-Pozo SE, Schold J, Nakagawa T, Sanchez-Lozada LG, Johnson RJ, Lillo JL. Excessive fructose intake induces the features of metabolic syndrome in healthy adult men: role of uric acid in the hypertensive response. Int J Obes (Lond) 2010 Mar;34(3):454-461.

14. Yang Q, Zhang Z, Gregg EW, Flanders WD, Merritt R, Hu FB. Added sugar intake and cardiovascular diseases mortality among US adults. JAMA Intern Med 2014 Apr;174(4): 516-524.

15. Trinquart L, Merritt D, Galea, S. Why do we think we know what we know? A metaknowledge analysis of the salt controversy. Int J Epidemiol 2016 Feb 17. 